ysis, although a good recovery was made under the use of strychnia and iron. In this case the patient was a woman who nursed her child through diphtheria, but, as far as could be ascertained, did not have any membranes herself, although she complained of sore throat at the time. Trousseau, he said, had long ago described in the most admirable manner all the varieties and characteristics of diphtheritic paralysis, and there was no question in his own mind that the lesion in this affection might be either central or peripheral.

The chairman of the Section, Dr. W. R. Birdsall, said that as regards the pathology of diphtheritic paralysis he also believed that, while in many instances there was simply a neuritis, cases of undoubted central origin sometimes occurred. In the latter, however, the central lesion was apt to give rise also to peripheral degeneration. In adults diphtheritic paralysis was relatively more common than in children, and it very often occurred in cases in which the original attack of diphtheria was very light. As to the matter of heart failure, it was a question, he thought, whether the trouble was of the same nature as the paralysis noted after the acute attack, or was merely functional in character; and a point against its paralytic origin was the early stage at which it occurred. As regards the etiology of diphtheritic paralysis, it seemed to him entirely possible that it might be due to the original poison which caused the acute attack of the disease; the delay in its appearance being perhaps attributable to the comparatively long time which it takes for such toxic agents to act upon the nervous system.

In bringing the discussion to a close Dr. Thomson said that he had purposely refrained from taking up the subject of heart failure in the paper, for the reason that it was attended with so many complicating circumstances. He doubted very much, however, whether it was due to the same cause as the later paralyses. In many instances he believed that myo. carditis existed, and it seemed altogether probable that this was the fact, from the description given, in Dr. McLean's case. He had not touched upon the matter of therapeutics in the paper; but he quite agreed with Dr. McLean that electricity was of no value in diphtheritic paralysis. It was highly desirable, he said, to stimulate the peripheral extremities of the nerves, and this could best be accomplished by applying to the throat equal parts of honey and black pepper. In paralysis of the extremities a solution of pepper ( $\mathrm{I}$ drachm to the pint) was also a useful local application. As to Dr Putzel's criticism of his so-called post-latent period of diphtheria, Dr. Thomson said that the paralysis was to him an indication of certain processes going on subsequently to the acute stage, and that he could but again express his conviction that a similar post-latent stage was characteristic of all the acute fevers. This postlatent stage varied in its manifestations in the different diseases, and it seemed highly probable that its phenomena were due to the action of ptomaines.

The increase of diphtheria in this city of late years is clearly shown in some statistics recently published by the Health Department. From these it appears that during the ten years from $x 868$ to 1878 there were $I, 488$ deaths reported from diphtheria and croup, and during the ten years from 1878 to $1888,2,295$; the percentage of the total death-rate of the city being I. 52 in the former decade, and 1.72 in the latter.

The first Commencement of the College of Physicians and Surgeons in its new buildings was held May Io, when a class of 120 was graduated. On this occasion the first Harsen prize $(\$ 500)$, for the best examination in all the branches of study, was awarded to a son of Professor Henry B. Sands.

The New York Medico-Legal Society has begun to make preparations for an International Congress of Medical Jurisprudence to be held in this city in June, I 889 .

P. $R$ D

\section{CINCINNATI LETTER.}

Report of the Cincinnati Hospital; Mortality from Typhoid Fever and Sunstroke-Symploms in Typhoid Cases-Complications in Acute Rheumatism-Hemiplegia-Phthisis-Complications in Bright's Disease-Injuries followed by Tetanas-Obstetrical StatisticsDeath of Eminent Medical Men-Dr. C. D. Palmer.

The twenty-seventh annual report of the Cincinnati Hospital has just been issued, and it is the best report that has ever been issued from that institution. It gives evidence of much care in its arrangement and painstaking in the material selected for publication. The following quotation from the report of the medical staff will suffice to show where a large part of the credit for the admirable report belongs: "All of these cases have been car efully classified according to the nomenclature of the Royal College of Physicians of Lowdon, $\mathbf{1} \& 85$, in a very extended form, by Mr. P. Alfred Marchand, Registrar to the Staff, and it is hoped it will be regarded as an important contribution to the statistics of the general hospitals of the world."

In a previous letter it was mentioned that the clinical and Pathological School of the Cincinnati Hospital had become a department of the University of Cincinnati; and the report, in speaking of the union, says: "The organization authorized by your Board of the Staff Service, under the title of the Clinical and Pathological School of the Cincinnati Hospital, and its union with the Medical Department of the University of Cincinnati, has been most successfully accomplished, and as one result the number of students attending the course of clinical lectures has doubled, and thereby the income for the support of the Library and Pathological Museum has been increased by $\$$ rooo."

The total number of patients treated during the year amounted to 4,027 , of whom $35^{2}$ died; thus making a death-rate of 8.3 per cent. The deathrate for the previous year, ending Dec. 3I, 1886, was $8 \frac{3}{5}$ per cent. From this it appears that the deathrate for the year 1887 is $\frac{3}{10}$ per cent. higher than that of the preceding year.

The increased mortality may be largely explained, however, by a reference to the table of diseases. Here we find recorded 34 deaths from typhoid fever, 
and $\mathrm{i} 6$ from sunstroke. The large number of these cases that occurred during the year, and their mortality will be amply sufficient to account for the slightly higher death-rate.

The mortality from typhoid fever was 16.25 per cent. Thirty-four out of 209 cases terminated fatally. This mortality is not excessive for hospital cases, for a considerable proportion of the fatal cases were moribund when admitted. The type of typhoid fever that prevailed here during the early winter months was mild, and this factor must enter into consideration as helping to explain the low mortality.

The total number of medical cases treated during the year amounted to 1,937 , of surgical, 1,509 ; ophthalmological 206, and obstetrical and gynecological 390 . The average number of days of each patient's stay in the hospital was for medical patients I 7.58 days; surgical 30.3 1 days; ophthalmological $5^{\mathrm{I}}$ days, and obstetrical and gynecological 30.19 .

Some observations of interest as regards the symp toms and complications of particular diseases are also set forth in the report. For instance, in typhoid fever cases we learn that 152 out of 209 cases occurred in males. Diarrhœa was present in 78 of these cases; 37 had vomiting; 46 had cough; 37 had vomiting; 46 had cough; 35 had delirium (an unusually small proportion); 50 had sweating; 18 had epistaxis; 60 had rose-spots; 72 had gurgling; 52 had tympanitis; the highest pulse was 180; highest temperature iI 3.5 (?). Of the females, 23 had diarrhœa; 24 had vomiting; 18 had cough; 8 were delirious; I 3 had sweating; 7 had epistaxis; 22 had rose-spots; 25 had gurgling; 17 had tympanitis. The highest pulse was 190 ; temperature I05.4. One had perforation of the intestines; 2 had intestinal hæmorrhage; $\mathbf{r}$ had peritonitis; I had phlebitis; and I had diphtheria.

In the cases of acute rheumatism treated the following complications were noted: Twenty-eight had mitral insufficiency; I had chronic alcoholism; I had aortic insufficiency; I had erysipelas; 4 had mitral stenosis; I had mitral insufficiency, aortic stenosis and insufficiency; 2 had aortic stenosis; I had mitral stenosis and insufficiency; $r$ had pleuritic effusion.

Seven cases suffering with hemiplegia had syphilis and one had syphilitic cerebral thrombosis. One case of chorea was complicated by subacute rheumatism.

Among the phthisical cases there were found two who also had mitral insufficiency. This combination, is uncommon, but that valvular disease of the heart does sometime coexist with phthisis is proven by these statistics.

The complications noted as being found with Bright's disease are the following: Two had œedema of the brain and mitral insufficiency; I had acute gastritis; $r$ had tuberculosis; 2 had valvular disease of the heart; 2 had erysipelas, developed in the hospital; I had phthisis; I had mitral stenosis; I had delirium tremens, and I had mitral insufficiency.

A very interesting portion of the report is that devoted to the details of treatment adopted by each member of the Staff in typhoid cases. These reports are well written and carefully prepared, so that one can very profitably read them carefully, and perhaps obtain some ideas that may be of future service.

A feature of the surgical report that is at very great variance with the reports published abroad is in regard to character of injuries followed by tetanus. Nicolaier and Rossback in some statistics showed that tetanus usually, in fact almost always, occurred in cases in which the lower extremities were the seat of wounds, and from this fact argued that the bacillus of tetanus was found in the earth; this report shows that the cases in which tetanus developed were confined exclusively to injuries of the hand and arm: thus one had a laceration of the hand; one had a lacerated wound of the index-finger, and one had a mashed hand.

The appendix to the obstetrical report furnishes some very interesting features, which will probably be of interest to many readers. There were 234 women delivered during the year; about 65 per cent. of whom were primiparæ; 20 per cent. were duiparæ; I had twelve previous pregnancies. The average age of the primiparæ was 21 years and ro months. The youngest primipara was $x 6$; the oldest 37 . The average age of the multiparæ was 25 years and io months. The youngest multipara was 17 and the oldest 42.

Average duration of labor.-Primiparæ: Ist stage I 6 hours, Io minutes; 2d stage $2{ }^{\prime} 20^{\prime \prime}$; 3 d stage $14^{\prime \prime}$. Multiparæ: Ist stage, I $10^{\prime} 15^{\prime \prime} ; 2 \mathrm{~d}$ stage, $2^{\prime}$ 1 $8^{\prime \prime} ; 3 \mathrm{~d}$ stage $12^{\prime \prime}$.

Presentations,-Primiparæ: vertex, 147 ; breech 6. Multiparæ: vertex 75 ; face 2 ; breech 3 ; footling $I$. Positions. - Primiparæ: S. O.A., 95; R. O.A., 45; R. O. P., 3; S. D.A., 4; R. D.P., I ; R. D. A., 2 ; unknown 3 .

Sex of children.-Primiparæ gave birth to 75 male and 75 female children; multiparæ to 45 male and 37 female. In two cases of twins both were females. Primiparæ: male children weighed $7^{2 / 3}$ pounds, and were $18 \mathrm{~J} / 4$ inches in length; female, weight 7 pounds and length 18 inches. Multiparæ: male, weight 7 pounds, 4 oz., and length, 16 inches; females, weight 7 pounds, $4 \mathrm{oz}$, and length $\mathrm{I} 8$ inches.

The heaviest male child $121 / 4$ pounds, the lightest 3 pounds; female, heaviest io pounds, lightest $3 \frac{\mathrm{T}}{2}$ pounds. Premature labor occurred in to cases.

These extracts from the report will serve to give a fair idea of the work of the past year, as well as to indicate the fact that much credit is due the resident physicians for their careful and painstaking preparation of the clinical histories.

During the past year the local profession has been singularly unfortunate in losing the services of four valuable members. Drs. Dun, Heighway Muscroft and Aub have been called away, and Dr. C. D. Palmer met with an accident, which to say the least, will incapacitate him for a considerable space of time. As these are all men who were prominent in medical work, men possessed of large experience and liberal views, it will be found a very difficult matter to fill their places. J. C. $\mathrm{O}$ 